\title{
The Efficient Biodiesel Production from Refined Palm Oil using Spinning Disc Reactor
}

\author{
A. MEEMONGKOL and W. APPAMANA
}

\begin{abstract}
The spinning disc reactor was designed for biodiesel synthesis from a refined palm oil using $\mathrm{NaOH}$. The effects of the catalyst concentration, total flow rate and rotational speed were investigated. Biodiesel yield as high as $96.1 \%$ could be achieved with a very short residence time of $2-3$ seconds at a methanol to oil molar ratio of $6, \mathrm{NaOH}$ concentration of $1.0 \mathrm{wt} \%$, total flow rate $260 \mathrm{ml} / \mathrm{min}$ and rotational speed of $1000 \mathrm{rpm}$ under operating temperature of $60^{\circ} \mathrm{C}$. The mechanical stirred reactor (MS) and spinning disc reactor processes (SDR) were also compared for biodiesel production and found that SDR are 800-900 times more time efficient as compared to the MS.
\end{abstract}

Keywords - Biodiesel, Mechanical stirred reactor, Residence time, Spinning disc reactor.

\section{INTRODUCTION}

Biodiesel is one most potential alternative energy it is renewable and curbing the greenhouse gas emissions [1]. Biodiesel is produced by transesterification of triglyceride with methanol and catalyst to produce fatty acid methyl ester (FAME) and glycerol as a byproduct, typically in a stirred tank batch reactor. However, transesterification of triglyceride was limited with mass transfer between triglycerides and methanol phase due to immiscibility of oil and alcohol. Therefore, the various efficient intensification reactors was proposed to diminish the mass transfer resistance and to enhance mixing efficiency and increase productivity [2, 3]. Spinning disc reactor is an interesting technology that have been developed as a process intensification technology, where rapid mass and heat transfer $[4,5]$.

An SDR consists of a rotating disc within a stationary housing. The fluid is introduced at the center of a rotating disc, producing a thin film with a high shear stress on the surface of the disc. These high shear forces can provide better mixing, thereby increasing mass and heat transfer and achieving a shorter residence time. In addition, SDR is used in other processes such as polymerization [6], synthesized $\mathrm{TiO}_{2}$ nanoparticles [7] , synthesized silver, [8] photocatalysis [9]. In this study, biodiesel was produced by transesterification of refined palm oil with methanol using sodium hydroxide $(\mathrm{NaOH})$ as a catalyst was in an SDR. The effects of the catalyst concentration, total flow rate and rotational speed were

Autcharaporn Meemongkol is with Department of Chemical and materials Engineering, Rajamangala University of Technology Thanyaburi, Pathumtani, 12110 THAILAND.

*Weerinda Appamana is with Department of Chemical and materials Engineering, Rajamangala University of Technology Thanyaburi, Pathumtani, 12110 THAILAND.. investigated.

\section{EXPERIMENTAL}

A. Materials

Refined Palm Oil (RPO) was purchased from a local market in Thailand. Methanol (>99.8\% purity) was purchased from Thermo Fisher Scientific (Thailand). $\mathrm{NaOH}$ ( $>99.8 \%$ purity) was purchased from Ajax Fine Chem (Thailand). The standards for FAME contained methyl esters (Methyl heptadecanoate > $99.0 \%$ purity) was purchased from Sigma-Aldrich.

\section{B. Transesterification Reaction Procedure}

The design of the spinning disk reactor is shown in Fig. 1.

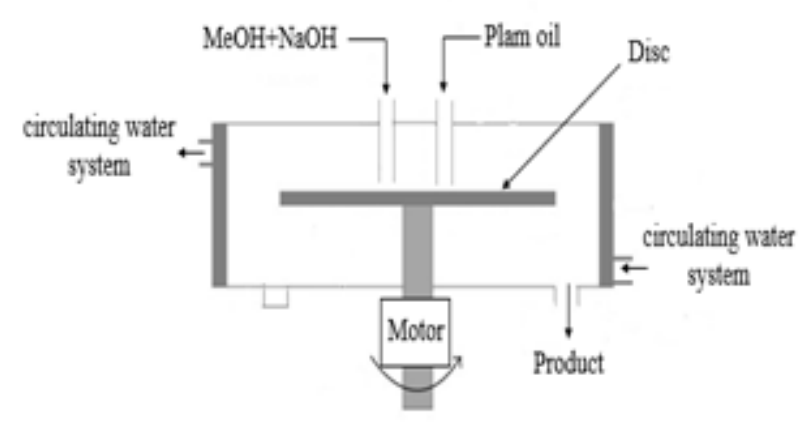

Fig. 1. shows the main structure of an SDR

The reactor comprising feed system inside disc driven by a motor and temperature controlled by circulating hot water system. Biodiesel was produced by transesterification of refined palm oil with methanol in an SDR. The $\mathrm{NaOH}$ was used as a catalyst. Both raw materials was fed into the SDR using a peristaltic pump. The two liquid streams from the distributors entered at the disc center was generated a thin film by centrifugal force. The collected sample exited through the reactor bottom was reduce the temperature to stop the reaction and centrifuged to separate the catalyst then the sample was washed with water to remove the catalyst and other impurities. The upper layer consisted of methyl esters and unconverted triglyceride was analyzed by gas chromatography (GC).

In a mechanical stirred reactor (MS), a three-necked glass reactor $250 \mathrm{ml}$ round bottom flask was equipped with a condenser circulated with cold water from an ice bath, fixed on a hot plate magnetic stirrer with constant stirring at a chosen temperature, a thermometer and a sampling valve as illustrated in the previous literature [1]. 


\section{Analysis}

The methyl esters yield was analyzed according to EN 14103 using a Perkin Elmer gas chromatography with FID equipped with a ZB5-HT capillary column $(0.25 \mathrm{~mm} \times 30 \mathrm{~m})$. Helium was used as a carrier gas. The oven temperature ramp program was started from $150{ }^{\circ} \mathrm{C}$ and held for $5 \mathrm{~min}, 170{ }^{\circ} \mathrm{C}$ with a rate of $10{ }^{\circ} \mathrm{C} / \mathrm{min}$ and held for $5 \mathrm{~min}, 220^{\circ} \mathrm{C}$ with a rate of $3{ }^{\circ} \mathrm{C} / \mathrm{min}$. Samples were prepared by dissolving $0.05 \mathrm{~g}$ of standard and $0.25 \mathrm{~g}$ of product in $5 \mathrm{ml}$ heptane. Temperatures of the injector and detector were $250{ }^{\circ} \mathrm{C}$. Methyl ester yield was calculated by Eq. (1):

$$
\% \text { Yield }=\frac{\left(\sum A\right)-A_{\mathrm{El}}}{A_{\mathrm{El}}} \times \frac{C_{\mathrm{El}} \times V_{\mathrm{El}}}{m} \times 100 \%
$$

where $\sum \mathrm{A}$ is total peak area, $\mathrm{A}_{\mathrm{EI}}$ is the peak area that corresponds to methyl heptadecanoate, $\mathrm{C}_{\mathrm{EI}}$ is the concentration of the methyl heptadecanoate solution $(\mathrm{mg} / \mathrm{mL}), \mathrm{V}_{\mathrm{EI}}$ is the volume of methyl heptadecanoate $(\mathrm{mL})$ and $\mathrm{m}$ is the mass of the biodiesel sample (mg) [10]

\section{RESUlTS AND DISCUSSIONS}

\section{A. Effects of the catalyst concentration on FAME yield}

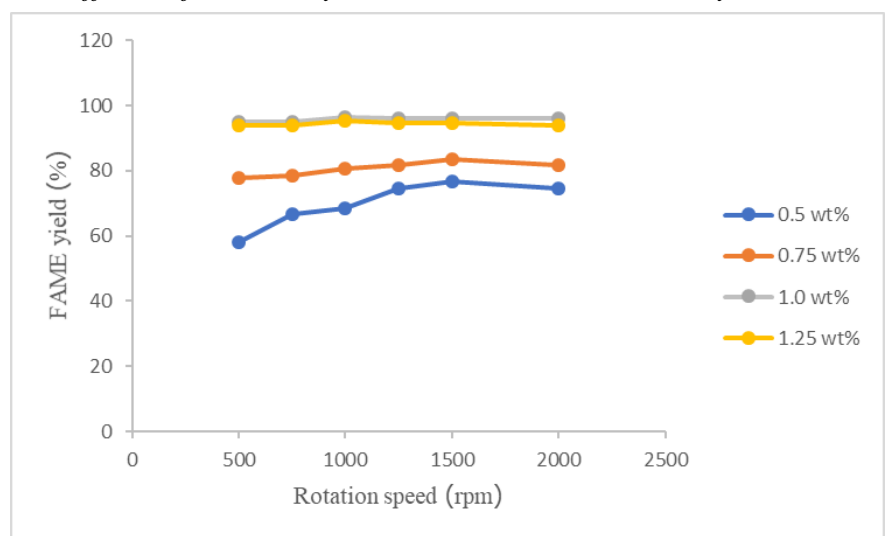

Fig. 2. Effect of catalyst loading on FAME yield using SDR for refined palm oil

Selection of catalysts in transestersification reaction has an important part for determining in biodiesel production process. Due to removal of a catalyst from a reaction mixture can cause a major problem and also affects the rate of reaction. In this work, $\mathrm{NaOH}$ with concentration of $0.5-1.25 \mathrm{wt} \%$ were investigated at a fixed methanol-to-oil molar ratio of 6 , temperature of $60^{\circ} \mathrm{C}$, rotational speed of 500-2,000 rpm and total flow rate of $130 \mathrm{~mL} / \mathrm{min}$. The effect of catalyst concentration on yield of FAME show in Figure 2. The biodiesel yield increased with increase in catalyst concentration and yield was maximal at $92.4 \%$ when the $\mathrm{NaOH}$ concentration was $1.0 \mathrm{wt} \%$. The transesterification reactions are catalyzed with $\mathrm{NaOH}$ alkali catalyst. When the catalyst concentration is low the amount of catalyst is insufficient to complete the reaction. Increasing the concentration of $\mathrm{NaOH} 1.0 \mathrm{wt} \%$ the amount of catalyst is sufficient to complete the reaction $[11,12]$. Increasing the concentration of $\mathrm{NaOH} 1.25 \mathrm{wt} \%$ reduced the FAME yield because the large amount of catalyst results in saponification and difficult separation of esters from glycerol and water [4].
Therefore, the subsequent experiments for biodiesel production were based on the condition of a catalyst loading of $1.0 \mathrm{wt} \%$.

\section{B. Effects of rotational speeds on FAME yield}

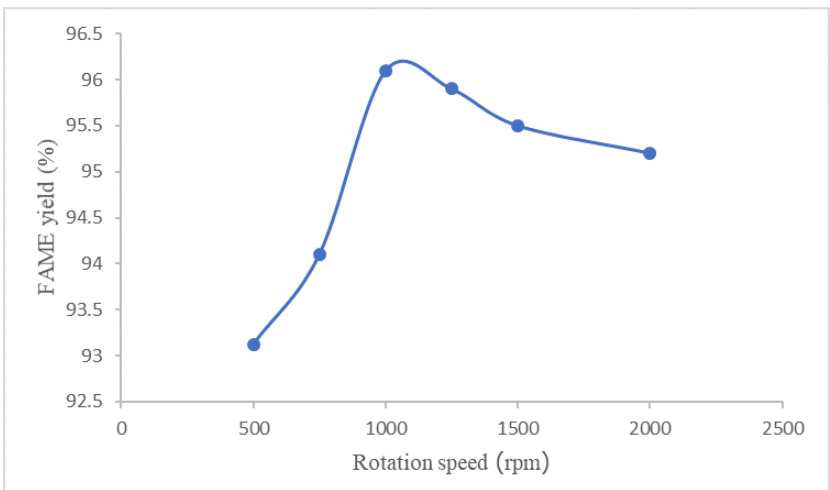

Fig. 3. Effect of rotational speed on FAME yield using SDR for refined palm oil

Figure 3 show the obtained FAME yield at various values of rotational speed between 500-2,000 rpm at a fixed methanol-to-oil molar ratio of 6 , temperature of $60 \circ \mathrm{C}$, total flow rate of $260 \mathrm{~mL} / \mathrm{min}$ and catalyst loading of $1.0 \% \mathrm{wt}$. Biodiesel production with SDR at rotation speeds which is a affecting the reaction because the rotation speeds is related to the residence time. The FAME yield significantly increased from $93.12 \%$ to $95.20 \%$ when rotational speed was increased from $500 \mathrm{rpm}$ to $1,000 \mathrm{rpm}$. The FAME yield enhancement could be attributed to the improved mass transfer and micro-mixing efficiency by centrifugal force in an SDR, thin liquid film and a vigorous flow are generated on the disc surface [4]. Therefore, the intensive mixing increased the contact between the two immiscible reactants, increasing mass transfer and enhancing overall reaction rate during the transesterification. Resulting in high biodiesel production can be done in SDR with short residence time [4, 13]. However, the FAME yield was found to decrease by further increasing the rotational speed over $1,000 \mathrm{rpm}$. This could be due to the shorter residence time of the reactants in the SDR. Therefore, the subsequent experiments for biodiesel production were based on the condition of a catalyst loading of $1.0 \mathrm{wt} \%$ of oil and rotating speed of 1,000 rpm.

\section{Effect of total flow rate on FAME yield}

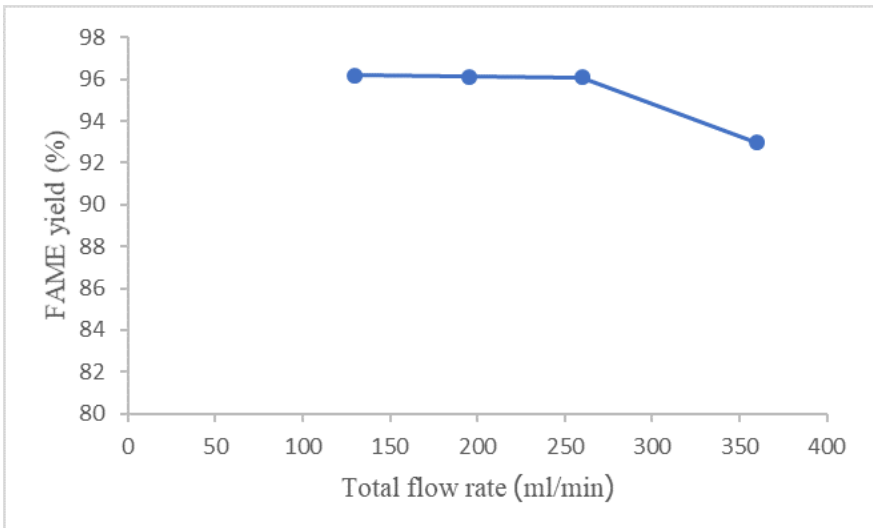

Fig. 4. Effects of the total flow rate on yield of FAME using SDR for refined palm oil. 
Figure 4 shown the obtained FAME yield at various values of total flow rate when all other operating parameters such as alcohol to oil molar ratio, catalyst concentration and rotational speed were kept constant. It can be clearly seen that an increase in total flow rate from 125 to $260 \mathrm{ml} / \mathrm{min}$ doesn't effect the FAME yield. However, the FAME yield was found to decrease by further increasing the total flow rate over 260 $\mathrm{ml} / \mathrm{min}$. This could be due to the shorter residence time of the reactants in the SDR. In addition, when the liquid flow rate increased, the film thickness on the disc surface increased, reducing the potential for mix reactant resulting in a decrease in the amount of FAME $[4,14]$.

\section{Comparative performance of reactor types on FAME yield} TABLE I. COMPARED REACTOR FOR BIODIESEL PRODUCTION

\begin{tabular}{lcccc}
\hline \hline REACTOR & Oil & Catalyst & Time & $\begin{array}{c}\text { \%FAME } \\
\text { yield }\end{array}$ \\
\hline MS[15] & $\begin{array}{c}\text { Refined Palm } \\
\text { Oil }\end{array}$ & $\begin{array}{c}1.0 \% \mathrm{wt} \\
\mathrm{KOH}\end{array}$ & $60 \mathrm{~min}$ & $88.0 \%$ \\
\hline MS (This work) & $\begin{array}{c}\text { Refined Palm } \\
\text { Oil }\end{array}$ & $\begin{array}{c}1.0 \% \mathrm{wt} \\
\mathrm{NaOH}\end{array}$ & $60.0 \mathrm{~min}$ & 92.0 \\
\hline SDR (This work) & $\begin{array}{c}\text { Refined Palm } \\
\text { Oil }\end{array}$ & $\begin{array}{c}1.0 \% \mathrm{wt} \\
\mathrm{NaOH}\end{array}$ & $\begin{array}{c}2-3 \\
\text { seconds }\end{array}$ & 96.1 \\
\hline \hline
\end{tabular}

To compare the reactor performance with other reactors with different mixing types. Table 1 summarizes the reaction time and FAME yield reported in literatures using refined palm oil as feedstocks. Eman N. Ali et al. reported the highest biodiesel yield of $88.0 \%$ for the mechanical stirred reactor operated at a methanol to oil molar ratio of $6,1.0 \mathrm{wt} \%$ catayst, $60^{\circ} \mathrm{C}$ operating temperature and $60 \mathrm{~min}$. In this study, a FAME yield as high as $96.1 \%$ could be achieved with a very short residence time of 2-3 s, which compares favorably with previously reported methods. Since SDR has an enhancement effect on the transesterification in terms of mixing immiscible liquids to reduce mass transfer resistance, the better results in term of FAME yield were obtained. Based on the similar conditions (temperature, amount of catalyst and molar ratio of methanol to oil), the biodiesel production using SDR operated can improve the production rate, resulting in a reduction in the operating cost.

\section{CONCLUSION}

This work, continuous biodiesel production from refined palm oil by using a spinning disc reactor (SDR) was investigated and compared to a mechanical stirred reactor. The transesterification was conducted under optimized conditions using a methanol-to-oil molar ratio of $6, \mathrm{NaOH}$ concentration of $1.0 \mathrm{wt} \%$, total flow rate $260 \mathrm{ml} / \mathrm{min}$ and rotational speed of $1000 \mathrm{rpm}$ under operating temperature of $60^{\circ} \mathrm{C}$. Biodiesel yield as high as $96.1 \%$. Compared to the mechanical stirred reactor, spinning disc reactor offers a significant reduction in the reaction time for the transesterification, proving that the SDR is a promising intensification reactor for economic continuous biodiesel production. Furthermore, a spinning disc reactor has a simple structure and easy to use for biodiesel production.

\section{ACKNOWLEDGMENT}

W.A. would like to thank the National Research Council of Thailand (NRCT) for research foundation scholarship in 2018 (No.256102A1650009). The authors would like to thank Rajamangala University of Technology Thanyaburi for support in this work.

\section{REFERENCES}

[1] T. Ahmad, M. Danish, P. Kale, B. Geremew, S.B. Adeloju, M. Nizami, M. Ayoub, Optimization of process variables for biodiesel production by transesterification of flaxseed oil and produced biodiesel characterizations, Renewable Energy, 139 (2019) 1272-1280. https://doi.org/10.1016/j.renene.2019.03.036

[2] G. Knothe, L.F. Razon, Biodiesel fuels, Progress in Energy and Combustion Science, 58 (2017) 36-59. https://doi.org/10.1016/j.pecs.2016.08.001

[3] Sahar, S. Sadaf, J. Iqbal, I. Ullah, H.N. Bhatti, S. Nouren, R. Habib ur, J. Nisar, M. Iqbal, Biodiesel production from waste cooking oil: An efficient technique to convert waste into biodiesel, Sustainable Cities and Society, 41 (2018) 220-226. https://doi.org/10.1016/j.scs.2018.05.037

[4] K.-J. Chen, Y.-S. Chen, Intensified production of biodiesel using a spinning disk reactor, Chemical Engineering and Processing: Process Intensification, 78 (2014) 67-72. https://doi.org/10.1016/j.cep.2014.02.009

[5] Z. Qiu, J. Petera, L.R. Weatherley, Biodiesel synthesis in an intensified spinning disk reactor, Chemical Engineering Journal, 210 (2012) 597-609. https://doi.org/10.1016/j.cej.2012.08.058

[6] Y. Mohammadi, A.S. Pakdel, M.R. Saeb, K. Boodhoo, Monte Carlo simulation of free radical polymerization of styrene in a spinning disc reactor, Chemical Engineering Journal, 247 (2014) 231-240. https://doi.org/10.1016/j.cej.2014.03.013

[7] S. Mohammadi, A. Harvey, K.V.K. Boodhoo, Synthesis of $\mathrm{TiO} 2$ nanoparticles in a spinning disc reactor, Chemical Engineering Journal, 258 (2014) 171-184. https://doi.org/10.1016/j.cej.2014.07.042

[8] C.Y. Tai, Y.H. Wang, Y.W. Kuo, M.H. Chang, H.S. Liu, Synthesis of silver particles below $10 \mathrm{~nm}$ using spinning disk reactor, Chemical Engineering Science, 64 (2009) 3112-3119. https://doi.org/10.1016/j.ces.2009.03.041

[9] A.J. Expósito, D.A. Patterson, W.S.W. Mansor, J.M. Monteagudo, E. Emanuelsson, I. Sanmartín, A. Durán, Antipyrine removal by TiO2 photocatalysis based on spinning disc reactor technology, Journal of Environmental Management, 187 (2017) 504-512. https://doi.org/10.1016/j.jenvman.2016.11.012

[10] I. Choedkiatsakul, K. Ngaosuwan, S. Assabumrungrat, Application of heterogeneous catalysts for transesterification of refined palm oil in ultrasound-assisted reactor, Fuel Processing Technology, 111 (2013) 22-28. https://doi.org/10.1016/j.fuproc.2013.01.015

[11] T. Eryılmaz, F. Aksoy, L. Aksoy, H. Bayrakçeken, F. Aysal, S. Şahin, M. Kadir Yeşilyut, Process optimization for biodiesel production from neutralized waste cooking oil and the effect of this biodiesel on engine performance, 2018.

[12] D.O. Onukwuli, L.N. Emembolu, C.N. Ude, S.O. Aliozo, M.C. Menkiti, Optimization of biodiesel production from refined cotton seed oil and its characterization, Egyptian Journal of Petroleum, 26 (2017) 103-110. https://doi.org/10.1016/j.ejpe.2016.02.001

[13] C.G. Dobie, MarijaVicevic, K.V.K. Boodhoo, An evaluation of the effectiveness of continuous thin film processing in a spinning disc reactor for bulk free-radical photo-copolymerisation, Chemical Engineering and Processing: Process Intensification, 71 (2013) 97-106. https://doi.org/10.1016/j.cep.2013.03.011

[14] D. Ghiasy, K.V.K. Boodhoo, M.T. Tham, Thermographic analysis of thin liquid films on a rotating disc: Approach and challenges, Applied Thermal Engineering, 44 (2012) 39-49.

https://doi.org/10.1016/j.applthermaleng.2012.04.006 
[15] E.N. Ali, C.I. Tay, Characterization of Biodiesel Produced from Palm Oil via Base Catalyzed Transesterification, Procedia Engineering, 53 (2013) $7-12$.

https://doi.org/10.1016/j.proeng.2013.02.002

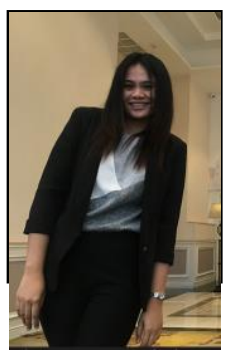

Autcharaporn Meemongkol was born in Phra Nakhon Si Ayutthaya, Thailand. Date of birth is Mar. 26, 1992. She studied in Rajamangala University of Technology Thanyaburi,Thailand. Master of Chemical Engineering Degree. Major field of study is chemical engineering subjects.

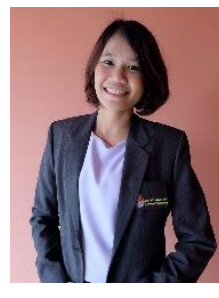

Weerinda Appamana was born in 1984. Now, she is an lecturer at Department of Chemical and materials Engineering, Rajamangala University of Technology Thanyaburi, Pathumtani, 12110 THAILAND. She earned her $\mathrm{PhD}$ degree in chemical engineering from Chulalongkorn University, Thailand. Dr. Weerinda Appamana is interested cover 1) waste to energy generation 2) intensification process 3) Catalysis and Catalytic Reaction Engineering 